\title{
Prevalence of gestational diabetes mellitus and its feto-maternal outcome in Kamla Nehru state hospital for mother and child, IGMC, Shimla, India
}

\author{
Aleeza Pal ${ }^{1 *}$, Bishan Dhiman², Rita Mittal'², Bhaskar J. Paul ${ }^{1}$ \\ ${ }^{1}$ Department of Obstetrics and Gynecology, Pandit Jawaharlal Nehru Medical College, Chamba, Himachal Pradesh, \\ India \\ ${ }^{2}$ Department of Obstetrics and Gynaecology, Kamla Nehru State Hospital for Mother and Child, Shimla, Himachal \\ Pradesh, India
}

Received: 07 September 2018

Accepted: 05 October 2018

*Correspondence:

Dr. Aleeza Pal,

E-mail: aleezapal16@gmail.com

Copyright: (c) the author(s), publisher and licensee Medip Academy. This is an open-access article distributed under the terms of the Creative Commons Attribution Non-Commercial License, which permits unrestricted non-commercial use, distribution, and reproduction in any medium, provided the original work is properly cited.

\begin{abstract}
Background: Gestational Diabetes Mellitus (GDM) is defined as carbohydrate intolerance of variable severity with the onset or first recognition during pregnancy. It is a disease entity that adversely affects maternal as well as fetal outcome. DIPSI guideline having suggested one-time plasma glucose level has emerged as a simple, practical and cheap method to detect GDM. This study was done to evaluate the prevalence of gestational diabetes using Diabetes in Pregnancy Study Group India (DIPSI) criteria and further assess its feto maternal outcome in Kamla Nehru State Hospital for Mother and Child, IGMC, Shimla.

Methods: This study was conducted in 500 patients between 24 and 28 weeks of gestation, attending the antenatal OPD. These patients were given $75 \mathrm{~g}$ oral glucose irrespective of last meal and their plasma glucose was estimated at $2 \mathrm{~h}$. Patients with plasma glucose $\geq 140 \mathrm{mg} / \mathrm{dl}$ were diagnosed as GDM and the rest as control or the non GDM group. The GDM patients were followed up and treated with medical nutrition therapy (MNT) and/or insulin therapy till delivery and maternal and fetal outcomes were then noted.

Results: The prevalence of GDM in this study was 6\%. Maternal and fetal complications were more in the GDM patients. Vaginal candidiasis and PROM were the common maternal complications, while hypoglycemia and hyperbilirubinemia were common in the fetuses.

Conclusions: GDM adversely affects the mother as well as fetus. DIPSI guideline having suggested a single plasma glucose level test has emerged as a practical and economical method to detect GDM.
\end{abstract}

Keywords: Fetomaternal outcome, Gestational diabetes mellitus pregnancy, Prevalence

\section{INTRODUCTION}

Gestational Diabetes Mellitus (GDM) is defined as carbohydrate intolerance of variable severity with the onset or first recognition during pregnancy.1GDM poses a risk to the mother as well as child of developing diabetes in future life and is associated with increased incidence of pre-eclampsia and operative interference whereas the fetus stands the risk of shoulder dystocia, birth injuries, congenital malformations, macrosomia, growth restriction, respiratory distress syndrome, polycythemia, hypoglycemia, hypocalcaemia and hypomagnesaemia. ${ }^{1-5}$

The overall prevalence of diabetes mellitus is on the rise, including India because of increasing urbanization, sedentary lifestyle, unhealthy dietary patterns, and the obesity epidemic. Higher incidence of GDM is seen in 
patients with increasing age, higher socio-economic status, higher pre-pregnancy weight and BMI, family history of diabetes or hypertension and past history of GDM. ${ }^{1-5}$

As we know India is very heterogeneous in its topography, living conditions, socio-economic levels and dietary habits, it is difficult to predict a uniform prevalence level. In a study done in Western Rajasthan, the prevalence of gestational diabetes mellitus was $6.6 \%{ }^{6}$ Universal screening should be the rule to detect more cases of GDM. Hence, universal screening for GDM is essential, as it is generally accepted that women of Asian origin and especially ethnic Indians are at a higher risk of developing GDM and subsequent complications. To standardize the diagnosis of GDM, the World Health Organization (WHO) recommends 2 -hour $75 \mathrm{gm}$ oral glucose tolerance test (OGTT) with a value $\geq 140 \mathrm{mg} / \mathrm{dl}$ considered as GDM. ${ }^{7}$

Glucose concentrations will be affected little by the timing of the last meal in a normal glucose tolerant woman compared to a woman with GDM. After a meal, normal glucose tolerant women would be able to maintain euglycemia despite glucose challenge test, due to adequate insulin response. In case of GDM, glycemic level increases with a meal and also after glucose challenge test. This cascading effect is advantageous as this would not result in false-positive diagnosis of GDM. Diagnosing GDM with DIPSI causes least disturbance in a woman's routine activities as she need not be in the fasting state and serves as both screening and diagnostic procedure.

This single-step procedure has been approved by Ministry of Health, Government of India and also recommended by World Health Organization (WHO). ${ }^{7}$

\section{METHODS}

A prospective study was conducted at Kamla Nehru State Hospital for Mother and Child, IGMC, Shimla w.e.f from 1st August 2014 to 31st July 2015. A total of 500 women were screened for GDM which included all pregnant women with estimated gestational age b/w 24 and 28weeks attending ANC during the study period.

All women were informed about nature of study and those who consented were included in the study. All patients with a plasma glucose $(\mathrm{PG}) \geq 200 \mathrm{mg} / \mathrm{dl}$ after $75 \mathrm{~g}$ OGTT (overt diabetes), with a history of DM prior to onset of pregnancy or who were suffering from any chronic illness were excluded from study.

A proforma containing general information on demographic characteristics, socio-economic status (according to Kuppuswami classification), education level, parity, family history of diabetes in first degree relatives and past history of GDM was filled up for each woman. Pregnant women who were included in the study group were given $75 \mathrm{gm}$ oral glucose powder dissolved in $250-300 \mathrm{ml}$ of water, irrespective of their last meal timing. Then venous blood was drawn two hours later. The plasma glucose was estimated in the hospital laboratory by the GOD-POD method. If the levels were $\geq$ $140 \mathrm{mg} / \mathrm{dl}$ she was labelled as GDM and if $\geq 200 \mathrm{mg} / \mathrm{dl}$ as Overt Diabetes. GDM women composed present study group and non GDM formed the control group.

Women diagnosed as GDM were advised medical nutrition therapy (MNT) for two weeks. After two weeks of MNT, the patients were tested for their fasting and two hours post prandial blood glucose levels. Patients with fasting plasma glucose $\leq 90 \mathrm{mg} / \mathrm{dl}$ and post meal glucose $\leq 120 \mathrm{mg} / \mathrm{dl}$, were admitted and insulin started.

We started with 2 IU of Regular Insulin before each major meal and got their seven blood samples tested before and two hours after each major meal and at $3 \mathrm{am}$. After controlling the blood glucose values on a particular dose of Regular Insulin, Mixtard Insulin-(70:30) a mixture of long acting and intermediate acting insulin was started in divided doses of $2 / 3$ rd in the morning and $1 / 3$ rd in the evening half an hour before meal.

GDM patients were then extensively monitored throughout their pregnancy in antenatal period for maternal and fetal wellbeing. Apart from routine investigations, fetal surveillance was done in the form of a fetal echocardiography, Target Ultrasonography, Doppler Ultrasonography and a Biophysical profile (BPP).

During intranatal and postpartum period all patients were monitored, and findings recorded in the proforma attached. Perinatal outcome, reasons for admission of the baby in Neonatal Intensive Care Unit (NICU) if needed and condition after discharge from NICU was also documented. All the relevant findings were recorded over the proforma attached. The whole data collected was then analyzed.

\section{Statistical analysis}

Chi square test for proportion was used for comparing GDM and control. Odds ratios were calculated for different risk factors using bivariate and multiple logistic regression analysis.

\section{RESULTS}

A total of 500 subjects were studied at $24-28$ weeks of gestation for GDM using the DIPSI criteria. Out of 500 subjects,30 were diagnosed as GDM which formed the study group.

The remaining 470 subjects formed the non GDM or the control group. Most of the participants were in the age group 21-30 years $(456,91.20 \%)$. It was observed that $20 \%$ of the GDM patients were $\geq 30$ years compared to 
$2.55 \%$ in the non GDM group and this relationship was found to be statistically significant $(\mathrm{P}<0.05)$.

Table 1: Age distribution of subjects.

\begin{tabular}{|llllll|}
\hline Age & GDM & \multicolumn{2}{l}{ Non GDM } & P value \\
\hline No. & $\%$ & No. & $\%$ & \\
\hline 20 years & 0 & 0 & 26 & 5.53 & 0.18 \\
\hline 21-30 years & 24 & 80 & 432 & 91.92 & $<0.05^{*}$ \\
\hline 30 years & 6 & 20 & 12 & 2.55 & $<0.05^{*}$ \\
\hline
\end{tabular}

The prevalence of GDM was found to be higher in women belonging to urban areas $(60 \%, 18 / 30)$ compared to women from rural areas. As BMI increases to $\geq 25$, there is substantial increase in the number of patients with GDM which is $56.67 \%$ versus $14.90 \%$ in non GDM group.
Table 2: Residential background.

\begin{tabular}{|lllllll|}
\hline & GDM & \multicolumn{3}{c|}{ Non GDM } & P value \\
\hline & No. & $\%$ & No. & $\%$ & \\
\hline Rural & 12 & 40 & 338 & 71.92 & $<0.05^{*}$ \\
\hline Urban & 18 & 60 & 132 & 28.08 & $<0.05^{*}$ \\
\hline
\end{tabular}

Among GDM group, no patient belonged to class IV or V and $27 / 30(90 \%)$ subjects belonged to category I or II which clearly predicts that GDM is more common in higher socioeconomic group. 9/30 (30\%) women with GDM had positive family history compared to $11 / 470$ $(2.34 \%)$ women without GDM.

History of GDM in previous pregnancy was present in 14 women and 4 women out of these developed GDM again. This association was found to be significant $(\mathrm{P}<0.05)$.

Table 3: Body mass index.

\begin{tabular}{|c|c|c|c|c|c|c|c|}
\hline BMI & Tota & es $n=500$ & GDI & & Non & $=470$ & P value \\
\hline & No. & $\%$ & No. & $\%$ & No. & $\%$ & \\
\hline$<18.5$ & 102 & 20.4 & 0 & 0 & 102 & 20.40 & $<0.005^{*}$ \\
\hline $18.5-24.9$ & 311 & 62.2 & 13 & 43.33 & 298 & 63.40 & 0.05 \\
\hline$\geq 25$ & 87 & 17.4 & 17 & 56.67 & 70 & 14.89 & $<0.005 *$ \\
\hline
\end{tabular}

Table 4: Socioeconomic status.

\begin{tabular}{|c|c|c|c|c|c|c|c|}
\hline \multirow[t]{2}{*}{ Socioeconomic status } & \multirow{2}{*}{$\begin{array}{l}\text { Total no. of cases } \\
\text { No. }\end{array}$} & \multicolumn{3}{|c|}{ GDM patients, $\mathbf{N}=\mathbf{3 0}$} & \multicolumn{2}{|c|}{ Non GDM, N=470 } & \multirow[t]{2}{*}{ P value } \\
\hline & & $\%$ & No. & $\%$ & No. & $\%$ & \\
\hline Class I & 108 & 21.6 & 12 & 40 & 96 & 20.42 & 0.019 \\
\hline Class II & 141 & 28.2 & 15 & 50 & 126 & 26.80 & 0.010 \\
\hline Class III & 144 & 28.8 & 3 & 10 & 141 & 30.00 & 0.020 \\
\hline Class IV & 60 & 12.0 & - & - & 60 & 12.00 & 0.037 \\
\hline Class V & 47 & 9.4 & - & - & 47 & 10.00 & 0.098 \\
\hline
\end{tabular}

More number of patients i.e. $33.33 \%$ patients in the GDM group delivered prematurely (34-36w6d) compared to $5.10 \%$ in the non GDM group. In contrast, more non GDM subjects went beyond 40 weeks i.e. $9.79 \%$ compared to GDM group $(6.67 \%)$. More no. of patients in the non GDM group had normal vaginal delivery i.e. $77.66 \%$ compared to $46.67 \%$ GDM subjects.

Table 5: Period of gestation.

\begin{tabular}{|c|c|c|c|c|c|}
\hline \multirow{2}{*}{$\begin{array}{l}\text { Period of } \\
\text { gestation }\end{array}$} & \multicolumn{2}{|c|}{ GDM } & \multicolumn{2}{|c|}{ Non GDM } & \multirow[t]{2}{*}{$P$ value } \\
\hline & No. & $\%$ & No. & $\%$ & \\
\hline$<34$ weeks & 3 & 10.00 & 35 & 7.44 & 0.60 \\
\hline $34-36$ w6d & 10 & 33.33 & 24 & 5.10 & $<0.05^{*}$ \\
\hline $37-39$ w6d & 15 & 50.00 & 365 & 77.65 & $<0.05^{*}$ \\
\hline$>40$ weeks & 2 & 6.67 & 46 & 9.79 & 0.57 \\
\hline
\end{tabular}

Babies with birth weight $\geq 3500 \mathrm{~g}$ were more in the GDM cases $(20 \%)$ compared to non GDM group (6.38\%) (P value $<0.05)$ which was statistically significant. In the GDM patients there is increased incidence of macrosomia (birth weight $>4 \mathrm{~kg}$ ) which is evident from present study as well $(20 \%$ versus $6.38 \%)$ in the non GDM group which was statistically significant. (P value $<0.05)$.

Table 6: Mode of delivery.

\begin{tabular}{|llllll|}
\hline $\begin{array}{l}\text { Period of } \\
\text { gestation }\end{array}$ & GDM & \multicolumn{3}{l|}{ Non GDM } & $\begin{array}{l}\text { P } \\
\text { value }\end{array}$ \\
\hline No. & $\%$ & No. & $\%$ & \\
\hline $\begin{array}{l}\text { Instrumal vaginal } \\
\text { Caesarean }\end{array}$ & 14 & 46.67 & 365 & 77.66 & 0.60 \\
\hline \begin{tabular}{l} 
section \\
\hline
\end{tabular} & 7 & 23.33 & 75 & 15.96 & $<0.05^{*}$ \\
\hline
\end{tabular}


It was observed that the incidence of neonatal complications was significantly higher in the GDM group compared to the non GDM group $(83.33 \%$ vs $30 \%)$. It was seen that 12 neonates $(40 \%)$ born to GDM patients were admitted in NICU compared to only $11.06 \%$ in the non GDM group with statistical significance ( $P<0.05)$.

The reasons for NICU admission included RDS, Hypothermia and Birth asphyxia whose incidence was found more in the GDM group which was $10 \%, 10 \%$ and $6.67 \%$ compared to $2.13 \%, 3.19 \%$ and $5.74 \%$ respectively in the Non GDM group.

Table 7: Birth weight.

\begin{tabular}{|llllll|}
\hline \multirow{2}{*}{ Birth Weight } & \multicolumn{2}{l}{ GDM } & \multicolumn{2}{l}{ Non GDM } & P \\
& N=30 & \multicolumn{3}{l}{ N=470 } & value \\
\hline & No. & $\%$ & No. & $\%$ & \\
\hline$\leq 2499 \mathrm{~g}$ & 2 & 6.67 & 100 & 21.28 & 0.05 \\
\hline $2500-3499 \mathrm{~g}$ & 22 & 73.33 & 340 & 72.34 & 0.90 \\
\hline$\geq 3500 \mathrm{~g}$ & 6 & 20.00 & 30 & 6.38 & $<0.05^{*}$ \\
\hline
\end{tabular}

The risk of postpartum complications which included mainly postpartum haemorrhage and puerperal sepsis was higher in the GDM group which was $16.67 \%$ and $13.33 \%$ respectively compared to $11.4 \%$ and $2.34 \%$ in the non GDM group.

The results were statistically significant in cases of Puerperal sepsis (P value $<0.05$ ). $2 / 30$ patients $(6.67 \%)$ of
GDM patients gave birth to congenitally anomalous babies in comparison to $6 / 470(1.27 \%)$ non GDM patients and this difference was statistically significant $(\mathrm{P}<0.05)$.

Table 8: Neonatal complications.

\begin{tabular}{|llllll|}
\hline $\begin{array}{l}\text { Neonatal } \\
\text { complications }\end{array}$ & GDM & \multicolumn{3}{l}{ Non GDM } & P \\
& No. & $\%$ & No. & $\%$ & \\
\hline Still Births & 2 & 6.67 & 8 & 1.70 & 0.06 \\
\hline RDS & 3 & 10.00 & 10 & 2.13 & $<0.05^{*}$ \\
\hline Hypothermia & 3 & 10.00 & 15 & 3.19 & 0.05 \\
\hline Birth asphyxia & 2 & 6.67 & 27 & 5.74 & 0.83 \\
\hline $\begin{array}{l}\text { Macrosomia } \\
\text { Shoulder }\end{array}$ & 3 & 10.00 & 14 & 2.98 & $<0.05^{*}$ \\
$\begin{array}{l}\text { Dystocia } \\
\text { Hypoglycemia }\end{array}$ & 6 & 6.67 & 0 & 0 & $<0.05^{*}$ \\
\hline $\begin{array}{l}\text { Hyperbilirubi } \\
\text { nemia }\end{array}$ & 4 & 13.33 & 25 & 5.80 & $<0.07$ \\
\hline $\begin{array}{l}\text { No } \\
\text { complication }\end{array}$ & 5 & 16.67 & 343 & 70.00 & $<0.05^{*}$ \\
\hline
\end{tabular}

Using bivariate analysis, odds ratios were calculated for risk factors found to be positively associated with GDM. The odds ratio was highest for socioeconomic status > upper middle class (10.05) followed by past history of GDM (9.20) and PROM (5.41).

Table 9: Maternal postpartum complications.

\begin{tabular}{|llllll|l|}
\hline Postpartum complications & GDM patients, $\mathrm{n}=\mathbf{3 0}$ & Non GDM patients, $\mathbf{n = 4 7 0}$ & \multicolumn{2}{c|}{ P value } \\
\hline & No. & $\%$ & No. & \% & \\
\hline Postpartum Haemorrhage & 5 & 16.67 & 40 & 8.51 & 0.16 \\
\hline Puerperal sepsis & 4 & 13.33 & 11 & 2.34 & $<.05^{*}$ \\
\hline No complication & 21 & 70.00 & 419 & 81.15 & 0.08 \\
\hline
\end{tabular}

\section{DISCUSSION}

The present prospective hospital-based study, which was the first of its kind to be undertaken in this part of the country, showed the prevalence of GDM as 6\%. GDM prevalence has been reported variably from 1.4 to $14 \%$ worldwide and differently among racial and ethnic groups. ${ }^{8}$

Findings of this study correlate well with the literature at the national as well as international level and hence Himachal Pradesh despite its varying ethnicity, topography and standards of living is very much a part of the diabetic spectrum the world over. The prevalence in the present study was comparable to the studies conducted by Wahi et al, Alpana et al, Rajput et al, Xiong et al and Kalra et al which was $6.5 \%, 5.7 \%, 7.1 \%, 2.5 \%$ and $6.6 \%$ respectively. ${ }^{9-12}$ In the present study, GDM was found to be associated with increasing age, higher BMI, family history of Diabetes and past history of GDM. Maximum subjects in the GDM group were above 25 years of age with the mean age 28.16 years. This was comparable to the studies done by Alpana et al, Kalra et al, Rajput et al. ${ }^{6,9,10}$ It was observed that among GDM patients,60\% (18/30) belonged to urban areas compared to $28.08 \%(132 / 470)$ in the non GDM group. This was comparable to the study done by Seshiah et al, where out of GDM subjects ,76.66\% belonged to the urban background and $23.34 \%$ to the rural background. ${ }^{7}$ History of GDM in previous pregnancy was found in $13.33 \%$ of the GDM group in the present study which was comparable to the study done by Kalra et al and Alpana et al where it was $12.12 \%$ and $13 \%$ respectively. ${ }^{6,9}$ Family history of Diabetes Mellitus has been reported to be associated with higher chances of developing GDM. ${ }^{10}$ 
In present study a significantly higher percent of women with GDM had positive family history of diabetes mellitus (30\%), comparable to the studies done by Chanu et al and Kalra et al where it was $36.1 \%$ and $33.33 \%$ respectively. ${ }^{6,13}$ A significant association of gestational diabetes mellitus was seen with socio-economic status of the subjects. It was observed in present study that most of the GDM women belonged to class I, II and III with not a single subject from class IV or class V. This association could be related to multiple factors such as higher maternal age, higher pre -pregnancy weight and BMI, more sedentary lifestyle in women of higher socioeconomic status. Yang et al did not find any association in Chinese pregnant women, while Rajput et al found a similar and significant association in a study conducted in Haryana where prevalence of GDM was found to be higher in women belonging to upper and upper middle class i.e. $25 \%$ and $16.8 \%$ respectively. ${ }^{10,14}$

Obesity is a significant risk factor for GDM, causing hormonal imbalance of carbohydrate regulation mechanism and insulin sensitivity. ${ }^{15}$ In present study, a significant proportion of subjects with GDM were overweight $[16(53.33 \%)]$ with a higher BMI $(\geq 25)$. It was higher in all the previous studies also, conducted by Alpana et al and Kalra et al.,

It was observed that there was increased incidence of obstetric complications in the GDM group which included gestational hypertension, vaginal candidiasis and Premature rupture of membranes in the GDM group with the incidence being $30 \%, 20 \%$ and $23.33 \%$ which was comparable to the study done by Kalra et al where it was $27 \%, 24.2 \%$ and $18.1 \%$ respectively. ${ }^{6}$ In the present study, the rate of caesarean section was higher in the GDM group $(23.33 \%)$ compared to the Non GDM subjects. This is in agreement with the studies done by Alpana et al and Wahi et al where it was $21.7 \%$ and $22.58 \%$ respectively. ${ }^{9,12}$ Whereas in the study done by Kalra et al, the incidence of caesarean section was $78.80 \%$ probably because of lack of adequate intrapartum fetal monitoring and surveillance techniques due to less infrastructure and greater patient load. ${ }^{6}$ Present study showed incidence of macrosomia as $16.67 \%$ in the GDM group which was comparatively higher than the non GDM patients $(2.98 \%)$.

This was in agreement to the study done by Kalra et al (18\%), while the study by Chanu et al had slightly higher rate i.e. $23 \% .^{6,13}$ Neonatal complications mainly still births, NICU admission, hypoglycaemia and hyperbilirubinemia being $6.67 \%, 26.67 \%, 20 \%$ and $13.33 \%$ respectively which was comparable to the study done by Kalra et al where it was $9.09 \%, 27.2 \%, 18 \%$ and $9.09 \%$ respectively. ${ }^{6}$

\section{CONCLUSION}

Very little data is available from Himachal Pradesh with regard to the prevalence of gestational diabetes mellitus
(GDM). The present study was therefore an attempt to evaluate the prevalence of Gestational Diabetes Mellitus, risk factors and fetomaternal outcome in the department of Obstetrics and Gynecology, Kamla Nehru State Hospital for Mother and Child, Indira Gandhi Medical College, Shimla.

GDM is a disease entity that adversely affects maternal as well as fetal outcome. DIPSI guideline having suggested one-time plasma sugar level has emerged as a simple, feasible and economical method to detect GDM. Treatment right after detection of GDM state is effective in stemming the adverse pregnancy outcomes.

\section{ACKNOWLEDGMENTS}

Authors would like to thank Dr. Bishan Dhiman and Dr. Rita Mittal, for their support during study.

Funding: No funding sources

Conflict of interest: None declared

Ethical approval: The study was approved by the Institutional Ethics Committee

\section{REFERENCES}

1. Diabetes, In: Williams OBSTETRICS. $23^{\text {rd }}$ edition. The McGraw-Hil Companies; Inc.2010:1106.

2. Schmidt MI, Duncan BB, Reichelt AJ, Branchtein L, Matos MC, Forti A, et al. For the Brazilian Gestational Diabetes Study Group. Gestational diabetes mellitus diagnosed with a 2-h 75 gm oral glucose tolerance test and adverse pregnancy outcomes. Diab Care. 2001;24(7):1151-5.

3. Seshiah V, Balaji V, Balaji MS, Sanjeevi CB, Green A. 3. Gestational diabetes mellitus in India. J Assoc Physicians India. 2004;52:707-11.

4. Zargar AH, Sheikh MI, Bashir MI, Masoodi SR, Laway BA, 4. Wani AI, et al. Prevalence of gestational diabetes mellitus in Kashmiri women from the Indian Subcontinent. Diabetes Res Clin Pract. 2004;66(2):139-45.

5. Seshiah V, Balaji V, Balaji MS, Paneerselvam A, Arthi T, et al. Prevalence of gestational diabetes mellitus in South India (Tamil Nadu) - a community based study. J Assoc Physicians India. 2008;56:32933.

6. Kalra P,Kachhwaha C, Singh H.Prevalence of gestational diabetes mellitus and its outcome in Western Rajasthan. Ind J Endo Metab 2013; 17(4):677.

7. Seshiah V, Sahay BK, Das AK, Shah S, Banerjee S, Rao PV, Ammini A, Balaji V, Gupta S, Divakar H, Misra S. Gestational diabetes mellitus-Indian guidelines. J Indian Medi Associat. 2009;107(11):799.

8. Bevier WC, Jovanovic-Peterson L, Peterson CM. Pancreatic disorders of pregnancy: diagnosis, management, and outcome of gestational diabetes. 
Endocrinol Metabol Clinic North Am. 1995;24(1):103-38.

9. Singh A, Uma B. Incidence of gestational diabetes mellitus and its outcomes in a rural population. $\mathrm{J}$ Evol Med Dental Sci. 2013;2(13):1982-7.

10. Rajput R, Yadav Y, Nanda S, Rajput M. Prevalence of gestational diabetes mellitus and associated risk factors at a tertiary care hospital in Haryana. Indian $\mathrm{J}$ Med Res. 2013;137(4):728.

11. Xiong X, Saunders LD, Wang FL, Demianczuk NN. Gestational diabetes mellitus: prevalence,risk factors, maternal and infant outcomes. Internet $\mathrm{J}$ Gynaecol Obstet. 2001;75(3):221-8.

12. Wahi P, Dogra V, Jandial K, Bhagat R, Gupta R, Gupta S, et al. Prevalence of gestational diabetes mellitus and its outcomes in Jammu region. J Assoc Physicians India 2011;59(4):227-30.

13. Chanu MM, Syiemleh AJ, Pradhan B, Devi RP Clinical Study of Fetomaternal Outcome of
Gestational Diabetes Mellitus. J Dent Med Sci.2015;14(4):53-6.

14. Yang X, Hsu-Hage B, Zhang H, Yu L, Dong L, Li J. et al. Gestational diabetes mellitus in women of single gravidity in Tianjin City, China. Diabetes Care 2002;25(5):847-51.

15. Latest evidence in gestational diabetes. In: Studd J, Tan S1, Chervenak FA, eds. Current Progress in Obstetrics and Gynaecology. Tree Life Media; 2012;1:40-41.

Cite this article as: Pal A, Dhiman B, Mittal R, Paul BJ. Prevalence of gestational diabetes mellitus and its feto-maternal outcome in Kamla Nehru state hospital for mother and child, IGMC, Shimla, India. Int J Reprod Contracept Obstet Gynecol 2018;7:4662-7. 